\title{
Anodic Behavior of Zn-Al-Be Alloys in NaCl Solution and the Influence of Be on Structure
}

\author{
Reza Amini ${ }^{1}$, Ziadolla Obidov², Izatulla Ganiev $^{2}$, Mohammad Razazi ${ }^{1}$ \\ ${ }^{1}$ Department of Material Science and Engineering, Islamic Azad University, Majlesi Branch, Isfahan, Iran; ${ }^{2}$ Tajikistan Academy of \\ Sciences, Chemistry Institute, Dushanbe, Tajikistan. \\ Email: reza.amini@mail.ru
}

Received October $24^{\text {th }}, 2011$; revised February $28^{\text {th }}, 2012$; accepted March $9^{\text {th }}, 2012$

\begin{abstract}
Potentiodynamic results of anodic behavior of $\mathrm{Zn} 5 \mathrm{Al}$ and $\mathrm{Zn} 55 \mathrm{Al}$ alloys, alloyed with Beryllium in the ambience of $\mathrm{NaCl}$ electrolyte and their microstructures are studied. They showed that a small addition of Beryllium (0.005 - 0.05 $\mathrm{wt} \%$ ) improves the corrosion resistance of $\mathrm{Zn} 5 \mathrm{Al}$ and $\mathrm{Zn} 55 \mathrm{Al}$ original alloys to $2-3$ times by changing grains shape to spherical and changing sizes to small grains. The proposed composition of Zinc-Aluminum alloy, which contains of Beryllium, can be used as anodic coatings to protect steel products and constructions against corrosion.
\end{abstract}

Keywords: Zn5Al; Zn55Al; Beryllium; NaCl Solution; Corrosion Resistant

\section{Introduction}

Metal coatings applied to surface of products by different methods. Currently, the method is used to protect steel and cast iron against the corrosion. Choice of coatings and application of techniques are determined by the operating requirements of reliability and durability of structures [1]. For many years, Zinc coating has been widely used to protect steel against corrosion in structures and equipment which are exposed to natural atmosphere. Many efforts have been made with the objective of identifying alternative coatings that could replace Zinc coatings with an advantage. As a result of those efforts, a new generation of coatings has been investigated which were basically made up of Zinc-Aluminum alloys.In recent years, the interest of researchers in the Zinc-Aluminum alloys is not reduced. The most versatile and common are two type of Zinc-Aluminum coating which are Galfan I (Zinc alloy with $5 \mathrm{wt} \%$ Aluminum) and Galfan II (Zinc alloy with $55 \mathrm{wt} \% \mathrm{Al}$ ) with high protective properties, which can be applied to hot methods by dipping steel into molten metal to cover it [2-4].

$\mathrm{Zn} 55 \mathrm{Al}$ coated steel sheets have an excellent corrosion resistance of two to five times that of galvanized steel sheets. Accordingly, the demand for Zn55Al coated steel sheets is expected to increase at an accelerated pace.

This paper shows the influence of additive Beryllium on the anodic behavior and microstructures of $\mathrm{Zn} 5 \mathrm{Al}$ and Zn55Al alloys, which are designed to apply protective coatings for hot method.

\section{Experimental Procedure}

Source of materials, which are used for this experiment are analytical grade of Zinc of H.D.A mark, Aluminum A7 grade alloyed with Beryllium $(2 \% \mathrm{Be})$. The alloys were obtained in crucibles, which made of Aluminum oxide in a shaft resistance furnace of SSHOL type in the temperature range about $750^{\circ} \mathrm{C}-800^{\circ} \mathrm{C}$. The alloys were casted into rods of graphite mold with a diameter of $8 \mathrm{~mm}$ and $140 \mathrm{~mm}$ heights. The bottom part was covered with a mixture of $50 \%$ rosin $+50 \%$ paraffin wax and all samples were investigated with the same prepared surface of the alloy. The frontal part was cleaned out of butt with sandpaper, polishing, degreasing, then it was etched in $10 \%$ solution of $\mathrm{NaOH}$, was thoroughly washed with alcohol and then was immersed in $\mathrm{NaCl}$ solution to study. Before immersing the sample in the solution, the cell was maintained to constant solution temperature $\left(+20^{\circ} \mathrm{C}\right)$ with MLSH-8 thermostat. Reference electrode was saturated with silver chloride and a subsidiary of a platinum electrode.

The investigations of electrochemical corrosion of anodic behavior of $\mathrm{Zn} 5 \mathrm{Al}$ and $\mathrm{Zn} 55 \mathrm{Al}$, which has been alloyed with Beryllium were conducted in the ambience of $\mathrm{NaCl}$ electrolyte with $0.03 \%, 0.3 \%$ and $3 \%$ concentrations by PI -50.1 .1 potentiostat with $2 \mathrm{mV} / \mathrm{sec}$ potential sweep rates $[5,6]$.

In the samples of electrochemical studies, potentiodynamic was polarized to the positive direction of the stationary potential, which was set when it was submerged before a sharp increase in the current due to create pit- 
tings. Then the samples were polarized in the opposite direction to $-1600 \mathrm{mV}$ potential, the protective oxidation layer of alloy has been produced on surfaces. Finally, the samples were polarized in the positive direction to get the potentiodynamic polarization curves of alloys and further to define the electrochemical parameters of Zinc-Aluminum alloys, which was alloyed with Beryllium. The cathodic curves were extrapolated before $-1.800--1.600 \mathrm{~V}$ potentials. Current corrosion densities was determined as the main characteristic electrochemical corrosion of process by the cathodic curve which was taken into the slope of the tofely line is equal to $b_{\mathrm{K}}=0.124 \mathrm{~V}$ [7]. Calculations of the corrosion current density (i, $\mathrm{A} / \mathrm{m}^{2}$ ) are carried out by the following equations:

$$
\mathrm{S}=\pi \mathrm{r}^{2} ; \mathrm{i}=\mathrm{I} / \mathrm{S},
$$

where $\mathrm{S}$ is the worked surface of a round specimens, $\mathrm{m}^{2}$; $\mathrm{I}$ is the strength of corrosion current, A.

Corrosion rate is a function of corrosion current, which is explained by the formula:

$$
\mathrm{K}=\mathrm{i}_{\text {corr }} \cdot \mathrm{k}
$$

where $\mathrm{k}$ is the electrochemical equivalent, the numerical value, which for Zinc is 1.22 (for $\mathrm{Zn} 5 \mathrm{Al}$ alloy) and 0.778 $\mathrm{g} / \mathrm{A} \cdot \mathrm{h}$ is the average of Zinc (1.22) and Aluminum (0.335) for $\mathrm{Zn} 55 \mathrm{Al}$ alloy, which the half is made of Aluminum. The obtained alloys were subjected to select gravimetric studies in ambience of $3 \% \mathrm{NaCl}$. Studies were carried out in accordance with the requirements of GOST 9.01786 which are described in the work of Romanov [8].
In metallographical studies, specimens were cut to cylindrical shape with $1 \mathrm{~cm} \times 1 \mathrm{~cm}$ sizes then they were sanded, polished, etched and dried then the test was carried out by AIS2100 Scanning Electron Microscope.

\section{Results and Discussion}

Table 1 shows results of the research of free corrosion potential in time for Zinc-Aluminum (Zn55Al alloy) on the concentration of Beryllium in three studied ambiences of $\mathrm{NaCl}$ electrolyte, which was fixed within an hour. There is a slight shift of potential to the positive range. It was seen that the formation of protective oxide film was completed for 30 minutes.

Studied results of the electrochemical corrosion of Zinc-Aluminum alloys with additive Beryllium have been presented in Tables $\mathbf{2}$ and $\mathbf{3}$. They show that the addition of Beryllium in small amounts (0.005 - $0.05 \mathrm{wt} \%)$ shifts the free corrosion potential $\left(-\mathrm{E}_{\mathrm{cv} . c o r r}, \mathrm{~V}\right)$ to the positive area and further increases the concentration of Beryllium, consistently displaces the potential Ecv.corrto the negative area. Such dependence is a characteristic of corrosion $\left(-\mathrm{E}_{\text {corr. }}\right)$, pitting $\left(-\mathrm{E}_{\mathrm{pt.}}\right)$ and repassiving $\left(-\mathrm{E}_{\text {rep. }}\right)$ potentials. Increasing the concentration of chloride ions due to decrease of free corrosion potential of $\mathrm{Zn} 55 \mathrm{Al}$ alloy with additive Beryllium. It indicates to decrease the corrosion resistance of alloys under the influence of chloride ions. The similar trend was occurred in all of the environments (Tables 2 and 3 ).

Table 1. Change in the free potential of corrosion $\left(-\mathrm{E}_{\text {free.corr. }}, \mathrm{V}\right)$ of $\mathrm{Zn55Al}$ alloy with additive Beryllium in the ambience of

\begin{tabular}{|c|c|c|c|c|c|c|c|c|c|}
\hline \multirow{2}{*}{ Ambience } & \multirow{2}{*}{ Content of Beryllium } & \multicolumn{8}{|c|}{ Time, $\min$} \\
\hline & & $1 / 3$ & $2 / 3$ & 1 & 5 & 15 & 30 & 45 & 60 \\
\hline \multirow{8}{*}{$0.03 \% \mathrm{NaCl}$} & - & 0.992 & 0.991 & 0.990 & 0.988 & 0.982 & 0.975 & 0.972 & 0.970 \\
\hline & 0.005 & 0.925 & 1.924 & 0.922 & 0.920 & 0.918 & 0.916 & 0.916 & 0.916 \\
\hline & 0.01 & 0.955 & 0.953 & 0.950 & 0.948 & 0.945 & 0.944 & 0.944 & 0.944 \\
\hline & 0.05 & 0.962 & 0.961 & 0.959 & 0.956 & 0.953 & 0.951 & 0.951 & 0.951 \\
\hline & 0.1 & 0.975 & 0.973 & 0.970 & 0.967 & 0.963 & 0.962 & 0.962 & 0.962 \\
\hline & 0.5 & 0.986 & 0.985 & 0.983 & 0.982 & 0.979 & 0.977 & 0.977 & 0.977 \\
\hline & 1.0 & 1.012 & 1.011 & 1.010 & 1.007 & 1.004 & 1.003 & 1.003 & 1.003 \\
\hline & 2.0 & 1.045 & 1.043 & 1.040 & 1.037 & 1.034 & 1.032 & 1.032 & 1.032 \\
\hline \multirow{8}{*}{$0.3 \% \mathrm{NaCl}$} & - & 1.022 & 1.022 & 1020 & 1.016 & 1.009 & 1.002 & 1.001 & 1.000 \\
\hline & 0.005 & 0.998 & 0.997 & 0.992 & 0.993 & 0.990 & 0.988 & 0.988 & 0.988 \\
\hline & 0.01 & 1.021 & 1.020 & 1.018 & 1.016 & 1.014 & 1.013 & 1.013 & 1.013 \\
\hline & 0.05 & 1.028 & 1.028 & 1.028 & 1.024 & 1.023 & 1.019 & 1.018 & 1.018 \\
\hline & 0.1 & 1.040 & 1.038 & 1.037 & 1.036 & 1.035 & 1.034 & 0.034 & 1.034 \\
\hline & 0.5 & 1.070 & 1.070 & 1.069 & 1.067 & 1.064 & 1.062 & 1.062 & 1.062 \\
\hline & 1.0 & 1.081 & 1.080 & 1.079 & 1.078 & 1.075 & 1.074 & 1.074 & 1.074 \\
\hline & 2.0 & 1.093 & 1.092 & 1.089 & 1.087 & 1.085 & 1.082 & 1.082 & 1.082 \\
\hline \multirow{8}{*}{$3 \% \mathrm{NaCl}$} & - & 1.041 & 1.040 & 1.037 & 1.032 & 1.027 & 1.021 & 1.020 & 1.020 \\
\hline & 0.005 & 1.015 & 1.014 & 1.013 & 1.010 & 1.007 & 1.006 & 1.005 & 1.005 \\
\hline & 0.01 & 1.030 & 1.030 & 1.029 & 1.026 & 1.023 & 1.022 & 1.022 & 1.022 \\
\hline & 0.05 & 1.036 & 1.035 & 1.034 & 1.032 & 1.029 & 1.028 & 1.028 & 1.028 \\
\hline & 0.1 & 1.051 & 1.050 & 1.049 & 1.047 & 1.045 & 1.043 & 1.043 & 1.043 \\
\hline & 0.5 & 1.074 & 1.073 & 1.071 & 1.069 & 1.067 & 1.033 & 1.066 & 1.066 \\
\hline & 1.0 & 1.027 & 1.027 & 1.025 & 1.022 & 1.020 & 1.118 & 1.118 & 1.118 \\
\hline & 2.0 & 1.175 & 1.174 & 1.172 & 1.168 & 1.165 & 1.163 & 1.163 & 1.163 \\
\hline
\end{tabular}
NaCl electrolytes in time. 
Table 2. Electrochemical properties of corrosion of $\mathrm{Zn} 5 \mathrm{Al}$ alloy, with additive Beryllium in the ambience of NaCl electrolytes in time.

\begin{tabular}{|c|c|c|c|c|c|c|c|}
\hline \multirow{3}{*}{ Ambience } & \multirow{3}{*}{$\begin{array}{c}\text { Content of Beryl- } \\
\text { lium } \\
\text { (wt } \%)\end{array}$} & \multicolumn{4}{|c|}{ Electrochemical properties } & \multicolumn{2}{|c|}{ Rate of corrosion } \\
\hline & & $-E_{\text {free.corr. }}$ & $-\mathrm{E}_{\text {corr. }}$ & $-E_{p a}$ & $-\mathrm{E}_{\text {rep }}$ & $\mathrm{I}_{\text {corr }} \times 10^{-2}$ & $\mathrm{~K} \times 10^{-3}$ \\
\hline & & \multicolumn{2}{|l|}{ Lire.corr. } & \multicolumn{2}{|c|}{$\mathrm{A} / \mathrm{M}^{2}$} & \multicolumn{2}{|c|}{$\mathrm{g} / \mathrm{m}^{2} \cdot \mathrm{h}$} \\
\hline \multirow{8}{*}{$0.03 \% \mathrm{NaCl}$} & - & 1.050 & 1.060 & 0.915 & 0.930 & 0.102 & 1.24 \\
\hline & 0.005 & 0.990 & 0.995 & 0.840 & 0.917 & 0.027 & 0.33 \\
\hline & 0.01 & 0.960 & 0.967 & 0.820 & 0.953 & 0.024 & 0.29 \\
\hline & 0.05 & 0.970 & 0.975 & 0.830 & 0.957 & 0.021 & 0.25 \\
\hline & 0.1 & 0.980 & 0.982 & 00.845 & 0.965 & 0.020 & 0.24 \\
\hline & 0.5 & 1.000 & 1.005 & 0.880 & 0.977 & 0.031 & 0.38 \\
\hline & 1.0 & 1.015 & 1.020 & 0.882 & 0.990 & 0.044 & 0.53 \\
\hline & 2.0 & 1.050 & 1.055 & 0.922 & 0.998 & 0.058 & 0.71 \\
\hline \multirow{8}{*}{$0.3 \% \mathrm{NaCl}$} & - & 1.070 & 1.080 & 0.935 & 0.950 & 0.105 & 1.28 \\
\hline & 0.005 & 1.012 & 1.017 & 0.875 & 0.936 & 0.030 & 0.36 \\
\hline & 0.01 & 0.971 & 0.978 & 0.900 & 0.959 & 0.027 & 0.33 \\
\hline & 0.05 & 0.975 & 0.977 & 0.907 & 0.962 & 0.023 & 0.27 \\
\hline & 0.1 & 0.992 & 0.995 & 0.919 & 0.970 & 0.022 & 0326 \\
\hline & 0.5 & 1.010 & 1.013 & 0.925 & 0.975 & 0.033 & 0.40 \\
\hline & 1.0 & 1.035 & 1.040 & 0.930 & 0.980 & 0.049 & 0.55 \\
\hline & 2.0 & 1.070 & 1.072 & 0.935 & 0.986 & 0.063 & 0.76 \\
\hline \multirow{8}{*}{$3 \% \mathrm{NaCl}$} & - & 1.100 & 1.115 & 0.965 & 0.980 & 0.109 & 1.33 \\
\hline & 0.005 & 1.055 & 1.060 & 0.910 & 0.950 & 0.038 & 0.46 \\
\hline & 0.01 & 1.020 & 1.025 & 0.915 & 0.940 & 0.034 & 0.41 \\
\hline & 0.05 & 1.027 & 1.033 & 0.920 & 0.945 & 0.031 & 0.37 \\
\hline & 0.1 & 1.038 & 1.040 & 0.928 & 0.957 & 0.030 & 0.36 \\
\hline & 0.5 & 1.059 & 1.068 & 0.939 & 0.965 & 0.042 & 0.51 \\
\hline & 1.0 & 1.090 & 1.095 & 0.970 & 0.900 & 0.057 & 0.65 \\
\hline & 2.0 & 1.108 & 1.110 & 0.978 & 0.996 & 0.072 & 0.87 \\
\hline
\end{tabular}

Table 3. Electrochemical properties of corrosion of Zn55Al alloy with additive Beryllium in the ambience of NaCl electrolytes.

\begin{tabular}{|c|c|c|c|c|c|}
\hline \multirow{3}{*}{ Ambience } & \multirow{3}{*}{$\begin{array}{c}\text { Content of } \mathrm{Mg} \\
\text { in the alloy }(\mathrm{wt} \%)\end{array}$} & \multicolumn{4}{|c|}{ Electrochemical properties } \\
\hline & & $-\mathrm{E}_{\text {free.corr. }}$ & $-\mathrm{E}_{\text {corr. }}$ & $-\mathrm{E}_{\mathrm{pa}}$ & $-\mathrm{E}_{\text {rep }}$ \\
\hline & & \multicolumn{4}{|c|}{$\mathrm{V}$} \\
\hline \multirow{7}{*}{$0.03 \% \mathrm{NaCl}$} & 0.005 & 0.916 & 0.925 & 0.811 & 0.829 \\
\hline & 0.01 & 0.944 & 0.951 & 0.815 & 0.858 \\
\hline & 0.05 & 0.951 & 0.965 & 0.832 & 0.863 \\
\hline & 0.1 & 0.962 & 0.973 & 0.840 & 0.874 \\
\hline & 0.5 & 0.977 & 0.985 & 0.874 & 0.881 \\
\hline & 1.0 & 1.003 & 1.007 & 0.890 & 0.902 \\
\hline & 2.0 & 1.032 & 1.040 & 0.893 & 0.914 \\
\hline \multirow{7}{*}{$0.3 \% \mathrm{NaCl}$} & - & 1.000 & 1.020 & 0.880 & 0.890 \\
\hline & 0.005 & 0.988 & 1.000 & 0.815 & 0.852 \\
\hline & 0.01 & 1.013 & 1.020 & 0.842 & 0.870 \\
\hline & 0.1 & 1.034 & 1.050 & 0.871 & 0.879 \\
\hline & 0.5 & 1.062 & 1.066 & 0.930 & 0.951 \\
\hline & 1.0 & 1.074 & 1.075 & 0.949 & 0.963 \\
\hline & 2.0 & 1.082 & 1.087 & 0.955 & 0.968 \\
\hline \multirow{8}{*}{$3 \% \mathrm{NaCl}$} & - & 1.020 & 1.040 & 0.900 & 0.920 \\
\hline & 0.005 & 1.005 & 1.012 & 0.840 & 0.874 \\
\hline & 0.01 & 1.022 & 1.030 & 0.863 & 0.925 \\
\hline & 0.05 & 1.028 & 1.039 & 0.865 & 0.927 \\
\hline & 0.1 & 1.043 & 1.050 & 0.874 & 0.944 \\
\hline & 0.5 & 1.066 & 1.073 & 0.945 & 0.972 \\
\hline & 1.0 & 1.118 & 1.120 & 0.958 & 0.985 \\
\hline & 2.0 & 1.163 & 1.165 & 0.975 & 0.103 \\
\hline
\end{tabular}


As an example, Figure 1 shows that the potentiodynamical anodic polarization curves of $\mathrm{Zn} 5 \mathrm{Al}$ alloys with additive Beryllium in the ambience of $3 \% \mathrm{NaCl}$ solution. Curves 2 - 4 are corresponded to the alloys with $0.005 \%$ $0.05 \%$ of additive Berylliums. They have been shifted tomore positive potential compared with curve 1 toward the base $\mathrm{Zn} 5 \mathrm{Al}$ alloy which is indicated to a lower rate of anodic dissolution of these alloys.

Potentiodynamic studies of anodic behavior of the alloy show that increasing concentration of Beryllium up to $0.05 \mathrm{wt} \%$ will make a gradual decreasing in the corrosion rate and further increasing concentrations of components of the alloy slightly increase the corrosion rate of the initial alloy, but the total value does not exceed the corrosion rate of the original alloy (Figure 2).

Microstructures of initial alloys, Zn5Al and Zn55Al alloys which alloyed with Beryllium are shown in Figure 3. They show that the additive Beryllium have a modifying influence on the structure of original alloys.

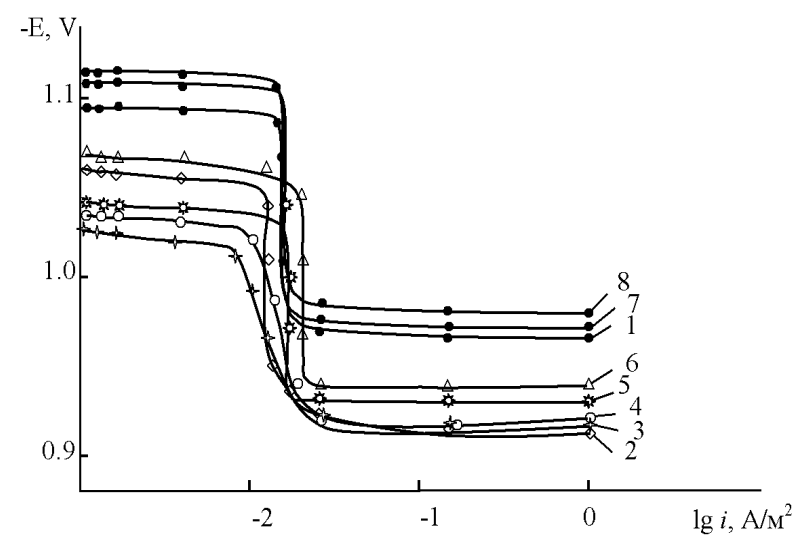

Figure 1. Potentiodynamic anodic polarization curves (rate of potential sweep is $2 \mathrm{mV} / \mathrm{s}$ ) of (1) $\mathrm{Zn} 5 \mathrm{Al}$ alloy, (2) $0.005 \%$ (3) $0.01 \%$ (4) $0.05 \%$, (5) $0.1 \%$, (6) $0.5 \%$, (7) $1.0 \%$ and (8) $2.0 \%$ wt $\%$ contained of Beryllium in the ambience of the $3 \% \mathrm{NaCl}$ electrolyte.

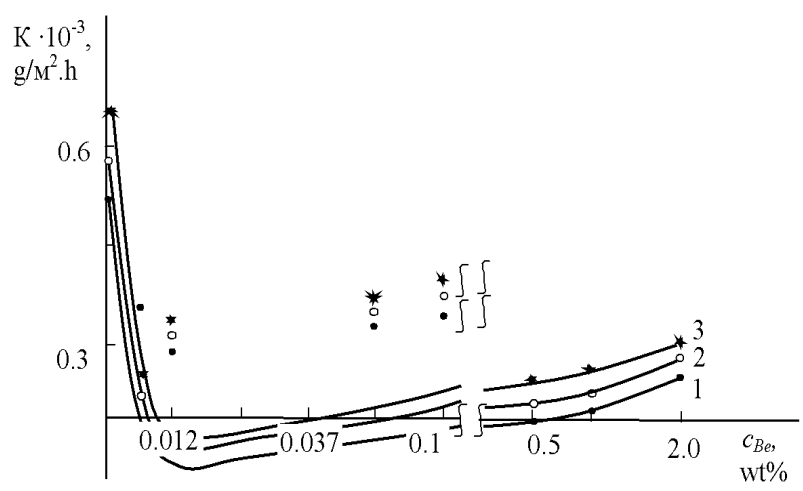

Figure 2. The influence of Beryllium content $\mathrm{C}$ (wt\%) on corrosion rate, $\mathrm{K}\left(\mathrm{g} / \mathrm{m}^{2} \cdot \mathrm{h}\right)$, of $\mathrm{Zn} 55 \mathrm{Al}$ alloy in the ambience of (1) $0.03 \%$, (2) $0.3 \%$ and (3) $3 \% \mathrm{NaCl}$ electrolytes.
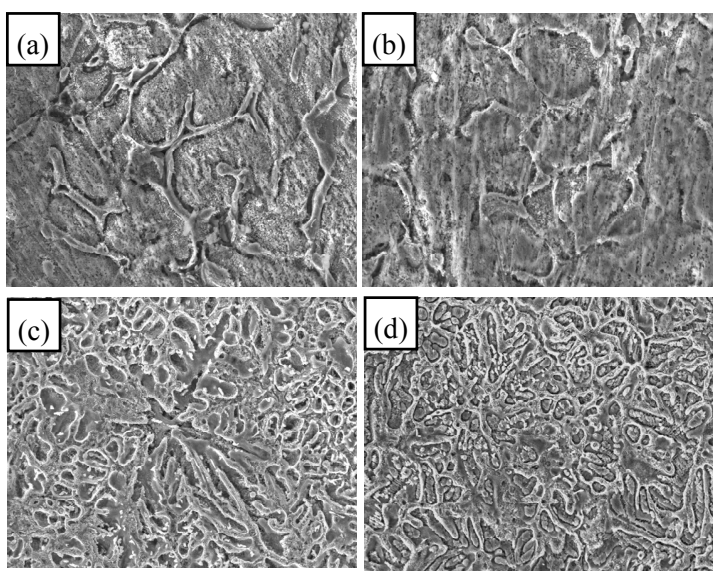

Figure 3. Microstructures (300×) of (a) Zn5Al, (b) with $0.05 \%$ Be, (c) Zn55Al and (d) with $0.05 \%$ Be.

Increasing content of Beryllium due to decrease grain size of Zinc in Aluminum $(\alpha-\mathrm{Al})$ and Aluminum in Zinc $(\gamma-\mathrm{Zn})$ solid solutions and change grain shapes to spherecal. In fact, there is not any literature and information about the phase diagram of Al-Zn-Be ternary systems and influence of Beryllium on Aluminum and Zinc, thus discussion is not possible in this paper. Although there is an anecdotal evidence of Al-Zn-Mg-Be quaternary systems [9]. It seems that Beryllium with Aluminum, Zinc and Magnesium in the quaternary alloys does not form a new phases and $\beta$-Be is formed free as a solid solution. Hence it should be expected that in $\mathrm{Zn} 55 \mathrm{Al}-\mathrm{Be}$ and $\mathrm{Zn} 5 \mathrm{Al}-\mathrm{Be}$ alloys and also in the form of solid solution in Aluminum $(\alpha-\mathrm{Al})$ and $\mathrm{Zinc}(\gamma-\mathrm{Zn})$ does not form a complex ternary phases.

Original alloys which compare with $\mathrm{Zn} 5 \mathrm{Al}$ and $\mathrm{Zn} 55 \mathrm{Al}$ alloys with additive Beryllium shows that alloys with Beryllium are characterized by smaller grains than $\mathrm{Zn} 5 \mathrm{Al}$ and $\mathrm{Zn} 55 \mathrm{Al}$ original alloys. It gives grounds to conclude that Beryllium is an effective modifier for these alloys and high corrosion resistant of the alloys, which is alloyed with Beryllium compared with the initial alloys is explained by the effect of modification of the original structure of $\mathrm{Zn} 5 \mathrm{Al}$ and $\mathrm{Zn} 55 \mathrm{Al}$ alloys.

Generally, potentiodynamic studies performed with $\mathrm{Zn} 55 \mathrm{Al}$ alloys on Beryllium showed that a small amount of it $(0.005-0.05 \mathrm{wt} \%)$ improves the corrosion resistance of the alloy in the initial alloy two to three fold. The proposed composition of Zinc-Aluminum alloy contained of Beryllium can be used as protective coatings to protect steel products and structures against the corrosion.

\section{Conclusion}

Changing regularities in the electrochemical properties of $\mathrm{Be}-\mathrm{Zn} 5 \mathrm{Al}$ and $\mathrm{Be}-\mathrm{Zn} 55 \mathrm{Al}$ alloys in the ambience of $\mathrm{NaCl}$ electrolyte with concentrations of $0.03 \%, 0.3 \%$ and 
$3 \%$, indicate that increasing the concentration of chloride ions in the electrolyte contributes to decrease the corrosion potential. It is determined that increasing concentration of the alloying element in alloys, the pitting and repassivating potentials shift to the positive area and increaseing concentration of chloride ions in the solution shift to the negative area. Corrosion rates of $\mathrm{Zn} 5 \mathrm{Al}$ and $\mathrm{Zn} 55 \mathrm{Al}$ alloys decreases 2 - 3 times in order to add Beryllium up to $0.05 \%$. It is explained by the effect of modification on the structure of original alloys, spherical shape of grains and small grain sizes.

\section{Acknowledgements}

This work was supported by department of Material Science and Engineering form Islamic Azad University, Majlesi Branch, Isfahan, Iran.

\section{REFERENCES}

[1] Z. Obidov and I. Ganiev, "Corrosion of $\mathrm{Al}+2.18 \% \mathrm{Fe}$ Alloys Alloyed with Gallium Group Elements," Lap Lambert Academic Publishing Gmbh \& Co. KG, Saar- brücken, 2011.

[2] A. P. Smiryagin, "Industrial of Non-Ferrous Metals and Alloys," Metallurgia, Moscow, 1981.

[3] V. A. Kechin and E. Y. Lublin, "Zinc Alloys," Metallurgia, Moscow, 1986.

[4] A. M. Shluger, F. F. Azhogin and E. A. Efimov, "Corrosion and Protection of Metals," Metallurgia, Moscow, 1981.

[5] T. M. Umarova and I. N. Ganiev, "Anodic Aluminum Alloys with Manganese, Iron and Rare-Earth Metals," Donish, Dushanbe, 2009.

[6] L. I. Freiman, V. A. Makarov and I. E. Bryksin, "Potentiostatic Methods in Corrosion Research and Electrochemical Protection," Y. M. Kolotyrkin, Kimia, 1972, p. 240.

[7] J. M. Kolotyrkin, "Metal and Corrosion," Metallurgia, Moscow, 1985.

[8] V. Romanov, "Methods of Studying Corrosion of Metals," Metallurgiya, Moscow, 1965.

[9] N. R. Bochvar and E. S. Kadaner, "The Phase Diagrams of Systems Based on Aluminum and Magnesium Handbook," Nauka, Moscow, 1977. 